\title{
Anxiety symptoms in a major mood and schizophrenia spectrum disorders
}

Karpov, B.

2016-09

Karpov , B , Joffe , G , Aaltonen , K, Suvisaari , J , Baryshnikov , I, Naatanen , P , Koivisto , M, Melartin , T , Oksanen , J , Suominen, K, Heikkinen, $M$, Paunio , T \& Isometsa , E 2016 , ' Anxiety symptoms in a major mood and schizophrenia spectrum disorders ' , European Psychiatry , vol. 37 , pp. 1-7 . https://doi.org/10.1016/j.eurpsy.2016.04.007

http://hdl.handle.net/10138/228035

https://doi.org/10.1016/j.eurpsy.2016.04.007

publishedVersion

Downloaded from Helda, University of Helsinki institutional repository.

This is an electronic reprint of the original article.

This reprint may differ from the original in pagination and typographic detail.

Please cite the original version. 
Original article

\title{
Anxiety symptoms in a major mood and schizophrenia spectrum disorders
}

\author{
B. Karpov ${ }^{\mathrm{a}, 1}$, G. Joffe ${ }^{\mathrm{a}, 1}$, K. Aaltonen ${ }^{\mathrm{a}, 1}$, J. Suvisaari ${ }^{\mathrm{b}, 2}$, I. Baryshnikov ${ }^{\mathrm{a}, 1}$, P. Näätänen ${ }^{\mathrm{a}, 1}$, \\ M. Koivisto ${ }^{\mathrm{a}, 1}$, T. Melartin ${ }^{\mathrm{d}, 3}$, J. Oksanen ${ }^{\mathrm{b}, 1}$, K. Suominen ${ }^{\mathrm{b}, \mathrm{c}, 4}$, M. Heikkinen ${ }^{\mathrm{a}, 1}$, \\ T. Paunio ${ }^{\mathrm{a}, \mathrm{b}, 1}, \mathrm{E}$. Isometsä ${ }^{\mathrm{a}, \mathrm{b}, *}$ \\ a Department of Psychiatry, University of Helsinki, Helsinki University Hospital, PO Box 22 (Välskärinkatu 12 A), 00014 Helsinki, Finland \\ ${ }^{\mathrm{b}}$ Institute for Health and Welfare, Department of Mental Health and Substance Abuse Services, Mannerheimintie 166, 00271 Helsinki, Finland \\ ${ }^{\mathrm{c}}$ Department of Social Services and Health Care, Helsinki, Finland \\ ${ }^{\mathrm{d}}$ Department of Psychiatry, Helsinki University Central Hospital, PO Box 590, 00029 Helsinki, Finland
}

\section{A R T I C L E I N F O}

\section{Article history:}

Received 26 January 2016

Received in revised form 7 April 2016

Accepted 12 April 2016

Available online 21 July 2016

\section{Keywords:}

Anxiety

Schizophrenia

Bipolar disorder

Depression

Comorbidity

\begin{abstract}
A B S T R A C T
Background: Comorbid anxiety symptoms and disorders are present in many psychiatric disorders, but methodological variations render comparisons of their frequency and intensity difficult. Furthermore, whether risk factors for comorbid anxiety symptoms are similar in patients with mood disorders and schizophrenia spectrum disorders remains unclear.

Methods: The Overall Anxiety Severity and Impairment Scale (OASIS) was used to measure anxiety symptoms in psychiatric care patients with schizophrenia or schizoaffective disorder (SSA, $n=113$ ), bipolar disorder (BD, $n=99$ ), or depressive disorder (DD, $n=188$ ) in the Helsinki University Psychiatric Consortium Study. Bivariate correlations and multivariate linear regression models were used to examine associations of depressive symptoms, neuroticism, early psychological trauma and distress, selfefficacy, symptoms of borderline personality disorder, and attachment style with anxiety symptoms in the three diagnostic groups.

Results: Frequent or constant anxiety was reported by $40.2 \%$ of SSA, 51.5\% of BD, and 55.6\% of DD patients; it was described as severe or extreme by $43.8 \%, 41.4 \%$, and $41.2 \%$ of these patients, respectively. SSA patients were significantly less anxious $(P=0.010)$ and less often avoided anxiety-provoking situations $(P=0.009)$ than the other patients. In regression analyses, OASIS was associated with high neuroticism, symptoms of depression and borderline personality disorder and low self-efficacy in all patients, and with early trauma in patients with mood disorders.

Conclusions: Comorbid anxiety symptoms are ubiquitous among psychiatric patients with mood or schizophrenia spectrum disorders, and in almost half of them, reportedly severe. Anxiety symptoms appear to be strongly related to both concurrent depressive symptoms and personality characteristics, regardless of principal diagnosis.
\end{abstract}

(C) 2016 Elsevier Masson SAS. All rights reserved.

\section{Introduction}

Anxiety symptoms are conceptualized as anxiety disorders (ADs) when they constitute specified syndromes and are intensive, recurrent, and impede an individual's psychosocial functioning

\footnotetext{
* Corresponding author. Tel.: +358 9 4711; fax: +3589 4716373.

E-mail address: erkki.isometsa@hus.fi (E. Isometsä).

1 Tel: +358 94711 .

2 Tel: +358295246000.

3 Tel: +358 9 4711; fax: +358947163735.

4 Tel: +358407718354
}

[1]. ADs are the most common psychiatric conditions in the general population, with typical estimates for lifetime prevalence of $16-28 \%$ [2-5]. ADs also commonly co-occur with other psychiatric conditions. For instance, up to $38 \%$ of patients with schizophrenia [6], $45 \%$ of patients with bipolar disorder [7], and $73 \%$ of patients with depression [8] reportedly suffer from a lifetime comorbid $\mathrm{AD}(\mathrm{s})$. ADs impair quality of life and are associated with poorer prognosis and outcome of psychotic and affective disorders [9-13]. This is true also for comorbid subthreshold anxiety [14-16]. Thus, careful recognition and proper treatment of comorbid anxiety, either as diagnosable disorders or as subthreshold states, are important in clinical practice. 
Abundant literature on anxiety disorder comorbidity among patients with major mental disorders exists $[6,17,18]$. The majority of these studies have focused on the presence of specific comorbid disorders [19], rarely reporting on subthreshold anxiety symptoms, even if clinically relevant. Few studies on comorbid anxiety disorders or symptoms have included both uni- and bipolar mood as well as non-affective psychotic disorders, and methodological variations have rendered comparisons of the results difficult. Hence, it remains unclear whether prevalence of anxiety symptoms and their putative risk factors are similar in patients with schizophrenia or schizoaffective disorder (SSA), bipolar disorder (BD), and depressive disorder (DD).

Anxiety and depressive disorders constitute the main internalizing mental disorders [20,21], with a high level of temporal covariation [22]. Recent studies have found that bipolar disorder shares some etiological and pathogenetic connections with the internalizing domain as well $[23,24]$. The internalizing disorders are likely to share most of their genetic basis [25-27]. The personality trait of high neuroticism is the most significant risk factor for internalizing pathology $[28,29]$ and a likely mediator of the underlying genetic diathesis for these disorders [30]. However, many other putative risk factors also contribute to the anxiety and depressive disorders. These factors include childhood and adolescence psychological trauma [31], low self-efficacy [32,33], borderline personality disorder [34], and negative experiences in close relationships [35]. Some findings indicate that the same factors could also affect the onset of schizophrenia and worsen its outcome [36-39]. However, whether similar covariation of depressive and anxiety symptoms exists and whether the same putative risk factors underlie anxiety in schizophrenia spectrum disorders and internalizing disorders remain unclear.

This study had both clinical and theoretical aims. The clinical aim was to compare the point prevalence of comorbid anxiety symptoms among psychiatric patients with depression, bipolar disorder, and schizophrenia or schizoaffective disorders. We hypothesized that the level of anxiety symptoms in patients with schizophrenia or schizoaffective disorder would be lower since, in contrast to mood disorders, these psychotic disorders are not diagnostically defined by the presence of negative affect as a central pathognomonic feature. The theoretical aim was to investigate the relationships of anxiety symptoms with neuroticism, depressive symptoms, and other putative risk factors. We expected that anxiety symptoms would show a clear association with these factors in patients with mood disorders, and explored whether the same relationships would apply to patients with schizophrenia spectrum disorders, in other words beyond the internalizing domain.

\section{Methods}

\subsection{Setting}

The current study was a part of the Helsinki University Psychiatric Consortium (HUPC) study performed in collaboration between the Faculty of Medicine, University of Helsinki; the Department of Psychiatry, Helsinki University Central Hospital; the Department of Health and the Mental Health Unit of the National Institute of Health and Welfare, Helsinki; the Department of Social Services and Health Care, Psychiatric Services, Helsinki; and the Department of Psychiatry, Helsinki City Health Department. The catchment area with 1,139,222 inhabitants in 2012 covered the metropolitan area of Helsinki, including the municipalities of Helsinki, Espoo, Vantaa, Kauniainen, Kerava, and Kirkkonummi. Specialized secondary mental health service is provided to these residents. The study was carried out in 10 community mental health centers, in 24 psychiatric inpatient units, in one day-care hospital, and in two residential communities. The HUPC study was approved by the Ethics Committee of Helsinki University Hospital and the pertinent institutional authorities.

\subsection{Sampling}

Stratified patient sampling was performed from 12 January 2011 to 20 December 2012. Patients were randomly drawn either by identifying all eligible patients on a certain day or week in a unit or from patient lists. Inclusion criteria were age from 18 to 64 years and provision of written informed consent. Patients with mental retardation, neurodegenerative disorders, and insufficient Finnish language skills were excluded. Of the 1361 eligible patients, 610 declined to participate and 304 were lost for other reasons. The final number of participants was 447, yielding a response rate of $33 \%$. For the current study, patients with a principal diagnosis of anxiety disorder, eating disorder, neuropsychiatric disorder, or substance use disorder $(n=47)$ were excluded from the final analyses due to the low number of patients in each group. The total number of patients, thus, was 400 .

\subsection{Diagnostic assessment}

Diagnostic assessments were made according to the International Statistical Classification of Diseases and Related Health Problems, 10th Revision [40] following the principle of lifetime main diagnosis. The authors (K.A, I.B., M.K., and B.K.) verified the clinical diagnoses given by attending psychiatrists by re-examining information obtained from all available medical records. In cases of any diagnostic uncertainty, the senior research psychiatrists (G.J. and E.I.) were consulted. Altogether, 69 cases were consulted. According to the principal diagnosis, patients were divided into three diagnostic groups: schizophrenia or schizoaffective disorder (SSA, $n=113$ ), bipolar disorder (BD, $n=99$ ), and depressive disorder (DD, $n=188$ ).

\subsection{Measurement of symptoms and traits}

Overall Anxiety Severity and Impairment Scale (OASIS) [41] is a brief, 5-item self-report questionnaire to assess severity and impairment associated with any anxiety disorder, multiple anxiety disorders, or subthreshold anxiety. The authors of the current article translated the OASIS into Finnish, which was then back translated into English and the translation revised in collaboration with the creator of OASIS, Dr. Sonya Norman. The questionnaire includes five questions regarding the frequency and severity of anxiety symptoms as well as anxiety-related avoidance behavior and decreased functioning at home/work/school and in social life. Responses range from zero (no anxiety or anxiety-related issues) to four (extreme anxiety and massive anxiety-related issues). A recommended cut-off score for screening of anxiety disorder is eight points [42]. Cronbach's alpha for OASIS in the total sample was 0.84 , and specifically, 0.88 for SSA, 0.86 for BD, and 0.78 for DD patients, showing good internal consistency overall and in the subgroups.

Beck Depression Inventory (BDI) [43] is a 21-item self-report questionnaire for measuring the severity of depression symptoms. The "Short Five" (S5) [44] is a 60-item questionnaire constructed for measuring 30 facets of the Five-Factor Model identified by the NEO (Neuroticism-Extraversion-Openness) Personality Inventory. The current study used six items describing neuroticism (S5N). The S5N scale as well as the other four scales (Extraversion, Openness, Agreeableness, and Conscientiousness) showed good internal consistency (Cronbach's alpha for S5N see below, other values not shown). The Experiences in Close Relationships-Revised 
questionnaire (ECR-R) [45] is a self-report 36-item measure of adult attachment style on anxiety and avoidance subscales. The General Self-Efficacy scale (GSE) [46] is a self-report 10-item instrument to assess perceived self-efficacy regarding stressful life events. The McLean Screening Instrument for Borderline Personality Disorder (MSI-BPD, hereafter MSI) [47] is a self-report 10item questionnaire to detect the possibility of borderline personality disorder (BPD). The Trauma and Distress Scale (TADS) $[48,49]$ is a self-report 43 -item scale for the assessment of early (childhood and early adulthood) traumatic experiences and distress. All of the scales had at least good internal consistency (Chronbach's alpha for BDI - 0.91; for S5N - 0.85; for ECR anxiety scale - 0.95 and avoidance scale - 0.97; for GSE - 0.93; for MSI 0.92 ; and for TADS - 0.80).

\subsection{Statistical analyses}

The differences between nominal sociodemographic variables across diagnostic groups were explored with Chi-square test, and between continuous variables with the Kruskal-Wallis test. Nominal dichotomous variables, such as sex, presence or absence of children, education ( primary or secondary and higher), smoking status, and care unit (in- or outpatients) were compared with mean OASIS scores using $t$-tests or Mann-Whitney $U$-tests; for marital status the Kruskal-Wallis test was used. The relationships between the OASIS and continuous variables (age, age of onset of illness, and duration of illness) were tested with bivariate correlation analysis. Age of onset and duration of illness were determined based on time of occurrence of the first symptoms reported by the patients. For investigation of the clinical hypothesis of the study, the differences between both the mean total scores and separate item scores of OASIS across the diagnostic groups the Kruskal-Wallis test was used. Bivariate correlation analysis (BCA; Spearman's coefficient) was used to estimate correlation of OASIS with BDI, S5N, MSI, GSE, TADS, and ECR anxiety and avoidance; analysis was performed for each group of patients separately. In order to test the theoretical hypothesis of the study, linear regression model was built to estimate the association between the OASIS (dependent variable) and measures correlated with it in BCA (independent variables) across all diagnostic groups. These measures were all of the abovementioned variables, with the exception of ECR avoidance. In addition, sex and age were included in the analysis. Separate regression models were constructed for each diagnostic group. As additional analysis and partly to avoid the problem of multicollinearity, regression analysis was performed for all independent variables and then with BDI and S5N excluded one at a time and simultaneously. Statistical significance was set at $P<0.05$. Statistical analysis was performed using the Statistical Package for the Social Sciences [50].

\section{Results}

\subsection{Sociodemographic and background data}

Table 1 shows the main sociodemographic characteristics of the sample. The patients were middle-aged and there was no significant difference in mean age between diagnostic groups $(P=0.112)$. The sex distribution differed markedly, with a preponderance of females in the DD and BD groups, but nearly equal distribution in the SSA group $(P<0.001)$. SSA patients had a family and children less often than BD and DD patients $(P<0.001)$. The proportion of childless patients in the DD group was higher than in the BD group. No significant differences in educational level or proportion of smokers were found. Of all the diagnostic groups, the SSA group had a highest proportion of inpatients.
Table 1

Sociodemographic and background characteristics of the sample.

\begin{tabular}{|c|c|c|c|c|c|c|c|c|c|}
\hline & \multicolumn{2}{|l|}{ SSA } & \multicolumn{2}{|l|}{$\mathrm{BD}$} & \multicolumn{2}{|l|}{ DD } & \multicolumn{2}{|c|}{ Total } & \multirow[t]{2}{*}{$P$-value } \\
\hline & $n$ & $\%$ & $n$ & $\%$ & $n$ & $\%$ & $n$ & $\%$ & \\
\hline Number & 113 & 28.2 & 99 & 24.8 & 188 & 47.0 & 400 & 100.0 & \\
\hline Female & 54 & 47.8 & 63 & 63.6 & 146 & 77.7 & 263 & 65.7 & $<0.001^{\mathrm{a}}$ \\
\hline Marital status & & & & & & & & & $<0.001^{\mathrm{b}}$ \\
\hline Married & 2 & 1.8 & 20 & 20.2 & 39 & 21.0 & 61 & 15.4 & \\
\hline Cohabitation & 8 & 7.3 & 17 & 17.2 & 29 & 15.6 & 54 & 13.7 & \\
\hline Divorced & 16 & 14.5 & 29 & 29.3 & 36 & 19.4 & 81 & 20.5 & \\
\hline Widowed & 3 & 2.7 & 1 & 1.0 & 3 & 1.6 & 7 & 1.8 & \\
\hline Unmarried & 81 & 73.6 & 32 & 32.3 & 79 & 42.5 & 192 & 48.6 & \\
\hline $\begin{array}{l}\text { Childless } \\
\text { patients }\end{array}$ & 97 & 89.0 & 58 & 59.8 & 130 & 70.7 & 285 & 73.1 & $<0.001^{\mathrm{a}}$ \\
\hline $\begin{array}{l}\text { Secondary/ } \\
\text { higher } \\
\text { education }\end{array}$ & 68 & 61.8 & 71 & 71.7 & 121 & 65.1 & 260 & 65.8 & $0.307^{\mathrm{a}}$ \\
\hline Smokers & 57 & 51.8 & 50 & 50.5 & 78 & 42.2 & 185 & 47.0 & $0.197^{\mathrm{a}}$ \\
\hline \multirow[t]{2}{*}{ Inpatients } & 36 & 31.9 & 20 & 20.2 & 34 & 18.1 & 90 & 22.5 & $0.028^{\mathrm{a}}$ \\
\hline & \multicolumn{2}{|c|}{ Mean (SD) } & \multicolumn{2}{|c|}{ Mean (SD) } & \multicolumn{2}{|c|}{ Mean (SD) } & \multicolumn{2}{|c|}{ Mean (SD) } & $P$-value \\
\hline Age & \multicolumn{2}{|c|}{$44.3(12.4)$} & \multicolumn{2}{|c|}{$43.4(12.3)$} & \multicolumn{2}{|c|}{$41.2(13.3)$} & \multicolumn{2}{|c|}{$42.6(12.9)$} & $0.112^{\mathrm{b}}$ \\
\hline Age of onset & \multicolumn{2}{|c|}{$30.4(13.1)$} & \multicolumn{2}{|c|}{$34.7(14.2)$} & \multicolumn{2}{|c|}{$35.2(14.3)$} & \multicolumn{2}{|c|}{$33.0(14.2)$} & $0.009^{\mathrm{b}}$ \\
\hline $\begin{array}{l}\text { Duration } \\
\text { of illness }\end{array}$ & \multicolumn{2}{|c|}{$14.6(13.8)$} & \multicolumn{2}{|c|}{$9.1(8.6)$} & \multicolumn{2}{|c|}{$6.3(4.8)$} & \multicolumn{2}{|c|}{$9.8(8.7)$} & $0.001^{\mathrm{b}}$ \\
\hline
\end{tabular}

SSA: schizophrenia or schizoaffective disorder; BD: bipolar disorder; DD: depressive disorder

a Chi-square test.

b Kruskal-Wallis test.

\subsection{Overall Anxiety Severity and Impairment Scale (OASIS)}

The mean scores of OASIS (Table 2) from 9.4 to 11.0 were seemingly close to each other, but nevertheless differed significantly $(P=0.040)$. Of specific subgroups, childless SSA and DD patients had higher OASIS scores $(P=0.001$ and $P=0.026$, respectively), as did smokers with $\mathrm{BD}(P=0.006)$. Analyses demonstrated no significant relations between OASIS scores and other sociodemographic and background variables (data not shown). Overall, from $40.2 \%$ to $55.6 \%$ of the patients of all groups reported experiencing anxiety frequently or constantly; from $41.2 \%$ to $43.8 \%$ felt anxiety as severe or extreme (Table 3 ). SSA patients felt frequent or constant anxiety less often than BD and DD patients $(P=0.010)$ and did not avoid anxiety-provoking situations as often as BD and DD patients $(P=0.009)$. Severe or extreme anxiety interfered with functioning at home, school, and work in $33.9 \%$ of SSA, $40.4 \%$ of BD, and $40.1 \%$ of DD patients (OASIS item 4 ). The corresponding figures for anxiety-induced impairment in social life and relationships were $35.7 \%, 33.4 \%$, and $44.3 \%$ (OASIS item 5). However, the differences between diagnostic groups in these two last items were not statistically significant.

Table 2

OASIS scores distributions: comparison between diagnostic groups.

\begin{tabular}{llll}
\hline & $\begin{array}{l}\text { SSA } \\
(n=113)\end{array}$ & $\begin{array}{l}\text { BD } \\
(n=99)\end{array}$ & $\begin{array}{l}\text { DD } \\
(n=188)\end{array}$ \\
\hline $\begin{array}{l}\text { Mean }{ }^{*}(\mathrm{SD}) \\
\text { Percentiles }\end{array}$ & $9.4(5.5)$ & $10.8(4.4)$ & $11.0(4.8)$ \\
10 & 4.0 & 4.0 & 4.0 \\
25 & 5.0 & 7.0 & 8.0 \\
50 & 10.0 & 12.0 & 12.0 \\
75 & 14.0 & 14.0 & 15.0 \\
90 & 16.0 & 16.0 & 17.0 \\
\hline
\end{tabular}

SSA: schizophrenia or schizoaffective disorder; BD: bipolar disorder; DD: depressive disorder.

$P=0.040$ (Kruskal-Wallis test). 
Table 3

Results of the OASIS questionnaire items by diagnostic group.

\begin{tabular}{|c|c|c|c|c|c|c|}
\hline & \multicolumn{2}{|c|}{ SSA $(n=113)$} & \multicolumn{2}{|c|}{$\mathrm{BD}(n=99)$} & \multicolumn{2}{|c|}{$\mathrm{DD}(n=188)$} \\
\hline & $n$ & $\%$ & $n$ & $\%$ & $n$ & $\%$ \\
\hline \multicolumn{7}{|c|}{ How often have you felt anxious ${ }^{*}$} \\
\hline No anxiety & 18 & 16.1 & 4 & 4.0 & 10 & 5.3 \\
\hline Infrequent anxiety & 21 & 18.8 & 15 & 15.2 & 29 & 15.5 \\
\hline Occasional anxiety & 28 & 25.0 & 29 & 29.3 & 44 & 23.5 \\
\hline Frequent anxiety & 32 & 28.6 & 41 & 41.4 & 76 & 40.6 \\
\hline Constant anxiety & 13 & 11.6 & 10 & 10.1 & 28 & 15.0 \\
\hline \multicolumn{7}{|c|}{ When you have felt anxious, how intense or severe was your anxiety } \\
\hline Little or None & 16 & 14.3 & 3 & 3.0 & 7 & 3.7 \\
\hline Mild & 18 & 16.1 & 20 & 20.2 & 35 & 18.7 \\
\hline Moderate & 29 & 25.9 & 35 & 35.4 & 68 & 36.4 \\
\hline Severe & 42 & 37.5 & 31 & 31.3 & 68 & 36.4 \\
\hline Extreme & 7 & 6.3 & 10 & 10.1 & 9 & 4.8 \\
\hline \multicolumn{7}{|c|}{$\begin{array}{l}\text { How often did you avoid situations, places, objects, or activities because of } \\
\text { anxiety or fear }\end{array}$} \\
\hline None & 23 & 20.4 & 14 & 14.1 & 20 & 10.6 \\
\hline Infrequent & 23 & 20.4 & 14 & 14.1 & 34 & 18.1 \\
\hline Occasional & 38 & 33.6 & 29 & 29.3 & 54 & 28.7 \\
\hline Frequent & 20 & 17.7 & 32 & 32.3 & 65 & 34.6 \\
\hline All the time & 9 & 8.0 & 10 & 10.1 & 15 & 8.0 \\
\hline \multicolumn{7}{|c|}{$\begin{array}{l}\text { How much did your anxiety interfere with your ability to do the things you } \\
\text { needed to do at work, at school, or at home }\end{array}$} \\
\hline None & 27 & 24.1 & 11 & 11.1 & 18 & 9.6 \\
\hline Mild & 17 & 15.2 & 21 & 21.2 & 36 & 19.3 \\
\hline Moderate & 30 & 26.8 & 27 & 27.3 & 58 & 31.0 \\
\hline Severe & 26 & 23.2 & 32 & 32.3 & 52 & 27.8 \\
\hline Extreme & 12 & 10.7 & 8 & 8.1 & 23 & 12.3 \\
\hline \multicolumn{7}{|c|}{ How much has anxiety interfered with your social life and relationships } \\
\hline None & 22 & 19.6 & 8 & 8.1 & 16 & 8.6 \\
\hline Mild & 22 & 19.6 & 24 & 24.2 & 46 & 24.6 \\
\hline Moderate & 28 & 25.0 & 34 & 34.3 & 44 & 23.5 \\
\hline Severe & 29 & 25.9 & 26 & 26.3 & 51 & 27.3 \\
\hline Extreme & 11 & 9.8 & 7 & 7.1 & 30 & 16.0 \\
\hline
\end{tabular}

SSA: schizophrenia or schizoaffective disorder; BD: bipolar disorder; DD: depressive disorder.

$P=0.010$

$P=0.009$ (Kruskal-Wallis test).

\subsection{OASIS correlation with other measures}

Overall, OASIS correlated mainly with the same scales in all groups (Table 4). The strong correlation between anxiety and depression symptoms was found in each diagnostic group. Noteworthy is that all patients experienced fairly severe depressive symptoms (data not shown). High neuroticism and anxiety correlated strongly in the SSA group and moderately in the BD and DD groups. In all patients, anxiety symptoms had a moderate direct correlation with the symptoms of borderline personality disorder

Table 4

Bivariate correlation between OASIS and other rating scales by diagnostic group (Spearman's rank).

\begin{tabular}{llllllll}
\hline & BDI & S5N & MSI & GSE & TADS & $\begin{array}{l}\text { ECR } \\
\text { anxiety }\end{array}$ & $\begin{array}{l}\text { ECR } \\
\text { avoidance }\end{array}$ \\
\hline SSA $(n=113)$ & $.700^{* * *}$ & $.712^{* * * *}$ & $.588^{* * *}$ & $-.448^{* * *}$ & $.498^{* * *}$ & $.350^{* *}$ & -.017 \\
BD $(n=99)$ & $.729^{* * * *}$ & $.569^{* * * *}$ & $.447^{* * * *}$ & $-.398^{* * *}$ & $.498^{* * * *}$ & $.365^{* * *}$ & $.232^{*}$ \\
DD $(n=188$ & $.700^{* * *}$ & $.584^{* * *}$ & $.457^{* * *}$ & $-.440^{* * *}$ & $.413^{* * *}$ & $.273^{* *}$ & $.203^{*}$
\end{tabular}

SSA: schizophrenia or schizoaffective disorder; BD: bipolar disorder; DD: depressive disorder; OASIS: Overall Anxiety Severity and Impairment Scale; BDI: Beck Depression Inventory; S5N: "Short Five" Neuroticism Scale; MSI: McLean Screening Instrument for Borderline Personality Disorder; GSE: General SelfEfficacy scale; TADS: Trauma and Distress Scale; ECR: Experiences in Close Relationships; ECR anxiety: ECR questionnaire items 1-18; ECR avoidance: ECR questionnaire items $19-36$.

$P \leq 0.05$.

** $P \leq 0.01$.

${ }^{* * * *} P \leq 0.001$.
(MSI) and early trauma (TADS), and a weak direct correlation with anxious attachment style (ECR anxiety). Across all the diagnostic groups, patients with more severe anxiety symptoms tended to have a lower self-efficacy level, as there was a moderate inverse correlation between OASIS and GSE. In addition, avoidant attachment style (ECR avoidance) showed a weak direct correlation with anxiety symptoms only in the BD and DD groups.

\subsection{Regression analysis}

Of all the variables, symptoms of depression (BDI) and high neuroticism ( $\mathrm{S} 5 \mathrm{~N})$ were the most strongly associated with OASIS in different regression models (Table 5). Surprisingly, in the main model with all the variables, neuroticism showed a significant weight in the SSA and DD groups, but not in the BD group. In the same model, depressive symptoms were significantly associated with OASIS in the BD and DD groups. When BDI and S5N were both excluded from the regression model, the symptoms of borderline personality disorder and level of self-efficacy acquired a regression weight in each diagnostic group and the early trauma and distress in the BD and DD groups.

\section{Discussion}

The current study investigated comorbid anxiety symptoms from both clinical and theoretical viewpoints. The clinical aim was to examine the point prevalence and level of comorbid anxiety symptoms across the major psychiatric disorders in specialized

Table 5

Clinical correlates for OASIS by diagnosis group (linear regression analysis). The main analysis showed in the first model (analysis with all variables).

\begin{tabular}{|c|c|c|c|c|c|c|}
\hline & \multicolumn{2}{|c|}{$\operatorname{SSA}(n=113)$} & \multicolumn{2}{|c|}{$\mathrm{BD}(n=99)$} & \multicolumn{2}{|c|}{$\mathrm{DD}(n=188)$} \\
\hline & B & Sig. & B & Sig. & B & Sig. \\
\hline \multicolumn{7}{|c|}{ Analysis with all variables } \\
\hline Sex & -.845 & .396 & -.647 & .370 & -.595 & .415 \\
\hline Age & -.005 & .900 & .037 & .219 & .036 & .127 \\
\hline BDI & .081 & .213 & .198 & .000 & .180 & .000 \\
\hline S5N & .148 & .007 & .086 & .053 & .094 & .007 \\
\hline MSI & .388 & .084 & .008 & .966 & .214 & .152 \\
\hline GSE & -.007 & .934 & .072 & .330 & .007 & .913 \\
\hline TADS & .011 & .674 & .029 & .094 & .021 & .110 \\
\hline ECR anxiety & .024 & .214 & .002 & .879 & -.014 & .271 \\
\hline \multicolumn{7}{|c|}{ Analysis with BDI excluded } \\
\hline Sex & -.815 & .415 & -.749 & .368 & -.499 & .540 \\
\hline Age & .001 & .981 & .053 & .126 & .037 & .159 \\
\hline S5N & .184 & .000 & .145 & .004 & .144 & .000 \\
\hline MSI & .410 & .069 & .124 & .565 & .257 & .122 \\
\hline GSE & -.017 & .836 & .002 & .979 & -.106 & .123 \\
\hline TADS & .019 & .456 & .050 & .011 & .043 & .003 \\
\hline ECR anxiety & .025 & .208 & .000 & .981 & -.020 & .170 \\
\hline \multicolumn{7}{|c|}{ Analysis with S5N excluded } \\
\hline Sex & -1.008 & .338 & -.888 & .222 & -.368 & .620 \\
\hline Age & -.014 & .741 & .022 & .450 & .038 & .117 \\
\hline BDI & .181 & .002 & .218 & .000 & .204 & .000 \\
\hline MSI & .585 & .011 & .169 & .331 & .382 & .007 \\
\hline GSE & -.090 & .257 & -.001 & .982 & -.061 & .320 \\
\hline TADS & .050 & .998 & .023 & .181 & .018 & .177 \\
\hline ECR anxiety & .031 & .129 & .012 & .450 & -.007 & .564 \\
\hline \multicolumn{7}{|c|}{ Analysis with BDI and S5N excluded } \\
\hline Sex & -1.042 & .356 & -1.202 & .163 & -.104 & .903 \\
\hline Age & -.002 & .969 & .029 & .402 & .041 & .145 \\
\hline MSI & .812 & .001 & .436 & .030 & .544 & .001 \\
\hline GSE & -.189 & .018 & -.144 & .045 & -.242 & .000 \\
\hline TADS & .017 & .554 & .043 & .035 & .043 & .005 \\
\hline ECR anxiety & .038 & .084 & .016 & .390 & -.010 & .511 \\
\hline
\end{tabular}

SSA: schizophrenia or schizoaffective disorder; BD: bipolar disorder; DD: depressive disorder; BDI: Beck Depression Inventory; S5N: "Short Five" Neuroticism Scale; MSI: McLean Screening Instrument for Borderline Personality Disorder; GSE: General Self-Efficacy scale; ECR anxiety: Experiences in Close Relationships questionnaire items 1-18; TADS: Trauma and Distress Scale. 
psychiatric care. Overall, almost half of the patients of all diagnostic groups experienced frequently or constantly severe or extreme anxiety. However, anxiety was somewhat less frequent in schizophrenia spectrum disorders (SSA) patients than in their mood disorders counterparts. The theoretical aim was to explore the relationship of anxiety with likely covariates and putative risk factors, and determine whether these are similar across the disorders investigated, which indeed they mostly were.

Strengths of the study include investigation of the similarities and differences in comorbid anxiety symptoms using the same methodology in a relatively large sample (total $n$ 400) of psychiatric patients with different principal diagnoses from the Helsinki metropolitan area psychiatric services. This enabled investigating the covariates and putative risk factors of anxiety symptoms across the major diagnostic groups simultaneously. Anxiety symptoms were measured using the Overall Anxiety Severity and Impairment Scale (OASIS), which have been found to be a valid and reliable brief scale [42]. In addition to frequency and intensity of anxiety symptoms and avoidance due to these symptoms, the OASIS also captures anxiety-related functional and behavioral impairment [51].

Our study had several limitations. First, it was a cross-sectional study, thus not enabling causal inferences regarding risk factors for anxiety symptoms, or any analyses of temporal variations. Second, we used only a self-report measure of anxiety symptoms and did not have interview-based measures of anxiety symptoms. Third, the response rate was only $33 \%$, probably due to sampling conducted during busy routine clinical practice and the length of the survey. However, according to the analysis of representativeness, our sample did not differ from the total patient population regarding age or gender. In terms of other demographic characteristics, our sample corresponded to the large screeningbased Vantaa Depression Study and Jorvi Bipolar Study $[18,52]$. Fourth, the presence, intensity, and quality of current psychotic symptoms were not measured, and thus, their role in comorbidity of anxiety remains unclear. Fifth, retrospective bias may exist in relation to some measurement scales, as patients may not always recollect past events and symptoms. Sixth, the principal clinical diagnoses were not based on structured interviews, although they were validated by the authors based on patients' psychiatric records. Seventh, the study includes multiple statistical analyses, so problems of multiple testing need to be considered. However, there were two hypotheses and one statistical test for each. The remaining analyses are either presented for descriptive purposes, or to confirm coherence and robustness of the hypothesis-related findings irrespective of methodological details.

The clinical aim of the study was to investigate prevalence and patterns of comorbid anxiety symptoms across the disorders. The mean OASIS total scores in all three subgroups clearly exceeded the cut-off score of eight points, usually indicating presence of an AD [42]. Nearly half of our patients in all groups frequently or constantly experienced severe or extreme anxiety. The proportions of our patients with frequent and severe anxiety were similar to findings of lifetime comorbid AD in the same diagnostic groups in earlier reports [6-8]. However, direct comparison of our results with those of previous studies is difficult due to methodological differences and since the published reports rely mostly on categorically diagnosed AD rather than on anxiety symptoms. Of all three subgroups, the SSA patients reported frequent anxiety and anxiety-related avoidance behavior less often than their mood disorder counterparts. The lower rate of comorbid anxiety symptoms in the SSA group could be explained in several ways. First, more frequent anxiety symptoms in patients with mood disorders could be expected because of strong co-incidence of internalizing disorders $[21,24-26]$ as well as temporal covariation of depressive and anxiety symptoms among them [22,53]. However, virtually all of the patients, irrespective of their principal diagnosis, suffered from clinically significant depressive symptoms, which strongly correlated with anxiety symptoms, albeit more in patients with mood disorders than in those with SSA. Second, the majority of SSA patients were outpatients, and thus, in relatively stable condition. For this reason, they probably less often had florid positive symptoms or primary disorder-induced anxiety symptoms to report [9]. Third, avoidance behavior may be less prominent in SSA patients due to their common withdrawal from social roles, and hence, less frequent exposure to common anxiety-provoking situations [54-56]. Furthermore, these patients often experience negative symptoms, rendering some of them emotionally numb and indifferent to situations that tend to cause anxiety in other populations [57]. Nevertheless, despite the observed subgroup differences, we found comorbid anxiety symptoms to be ubiquitous among psychiatric patients with major mood or schizophrenia spectrum disorders, and in almost half of them, reportedly severe. These findings highlight the importance of the recognition and treatment of comorbid anxiety symptoms.

The theoretical focus of our study was in investigating the clinical correlates of comorbid anxiety symptoms and their potential similarities across major psychiatric disorders. We found numerous quite similar associations; in addition to the strongest correlation of the OASIS score with symptoms of depression (BDI) and neuroticism (S5) in all patients, associations emerged also for low self-efficacy (GSE) and symptoms of borderline personality (MSI) across all diagnostic groups, and for early trauma and distress (TADS) in BD and DD patients. In multivariate regression analyses of all clinical variables, neuroticism in SSA patients was associated with comorbid anxiety symptoms as strongly as in DD patients. Therefore, the personality trait of neuroticism seems to be an underlying factor for comorbid anxiety beyond the internalizing domain, thus possibly also within schizophrenia spectrum disorders

Presence of depressive symptoms and high neuroticism, thus, persisted as independent covariates for anxiety symptoms in multivariate regression models. There were also other correlates associated with anxiety, but not consistently after controlling for the above two factors. These other correlates were mostly the same across the diagnostic groups, with only TADS not being associated with OASIS in the SSA group. Numerous studies suggest an association between experienced childhood trauma and psychotic and mood disorders $[31,37,58]$. Early traumatic experiences may be connected to a higher level of neuroticism as well $[59,60]$. Hence, trauma could potentially contribute to comorbid anxiety as a distal cause as well as a neuroticism-mediated condition. In addition, in our patients self-reported symptoms of borderline personality disorder were associated with anxiety symptoms in all diagnostic groups. This finding is consistent with other studies showing that up to $90 \%$ of patients with borderline personality disorder experience comorbid anxiety [34,61]. Probably unsurprisingly, also self-efficacy was inversely associated with the level of anxiety and regardless of the primary diagnoses. Poor self-efficacy appears to be a significant factor in development, severity, and treatment of anxiety disorders [32,62]. Our finding suggests that the same logic applies to comorbid anxiety as a continuum. In short, the broad similarity of correlates across all diagnostic groups supports the view that comorbid anxiety symptoms have numerous common background factors, and thus, could be due to a non-aligned condition rather than a direct consequence of the primary psychiatric pathology. While these associations are interesting, it is important to bear in mind their inconsistent significance in multivariate analyses. Analyses of mediation or moderation were beyond the scope of this study. Overall, the most robust and consistent associations with symptoms of anxiety in all subgroups were those with current depressive symptoms and neuroticism. 


\section{Conclusion}

Comorbid anxiety symptoms are highly prevalent among psychiatric patients with major mood or schizophrenia spectrum disorders, and in almost half of them, reportedly severe. The prevalence of symptoms is somewhat higher in the former group than in the latter. In addition, anxiety-related avoidance behavior is less frequent in patients with schizophrenia spectrum disorders. Anxiety symptoms appear strongly related to both concurrent presence of depressive symptoms and personality characteristics, particularly high neuroticism, regardless of the principal diagnosis.

\section{Disclosure of interest}

The authors declare that they have no competing interest.

\section{Acknowledgements}

The authors acknowledge the kind help of Dr. Sonya Norman in translation and backtranslation of the Finnish version of the Overall Anxiety Severity and Impairment Scale (OASIS).

\section{References}

[1] Öhman A. Fear and anxiety: overlaps and dissociations. In: Lewis M, HavilandJones JM, Barrett LF, editors. Handbook of emotions. New York: The Guilford Press; 2008. p. 709-30.

[2] Kessler RC, Chiu WT, Demler O, Walters EE. Prevalence, Severity, and comorbidity of twelve-month DSM-IV disorders in the National Comorbidity Survey Replication (NCS-R). Arch Gen Psychiatry 2005;62(6):617-27.

[3] Kessler RC, Aguilar-Gaxiola S, Alonso J, Chatterji S, Lee S, Ormel J, et al. The global burden of mental disorders: an update from the WHO World Mental Health (WMH) Surveys. Epidemiol Psichiatr Soc 2009;18(1):23-33.

[4] Wittchen HU, Jacobi F, Rehm J, Gustavsson A, Svensson M, Jönsson B, et al. The size and burden of mental disorders and other disorders of the brain in Europe 2010. Eur Neuropsychopharmacol 2011;21(9):655-79.

[5] Pirkola SP, Isometsä ET, Suvisaari J, Aro H, Joukamaa M, Poikolainen K, et al. DSM-IV mood-, anxiety- and alcohol use disorders and their comorbidity in the Finnish general population. Results from the Health 2000 Study. Soc Psychiatry Psychiatr Epidemiol 2005;40(1):1-10.

[6] Achim AM, Maziade M, Raymond E, Olivier D, Merette C, Roy MA. How prevalent are anxiety disorders in schizophrenia? A meta-analysis and critical review on a significant association. Schizophr Bull 2011;37(4):811-21.

[7] Pavlova B, Perlis RH, Alda M, Uher R. Lifetime prevalence of anxiety disorders in people with bipolar disorder: a systematic review and meta-analysis. Lancet Psychiatry 2015;2(8):710-7.

[8] Brown TA, Campbell LA, Lehman CL, Grisham JR, Mancill RB. Current and lifetime comorbidity of the DSM-IV anxiety and mood disorders in a large clinical sample. J Abnorm Psychol 2001;110(4):585-99.

[9] Braga RJ, Reynolds GP, Siris SG. Anxiety comorbidity in schizophrenia. Psychiatry Res 2013;210(1):1-7.

[10] El-Mallakh RS, Hollifield M. Comorbid anxiety in bipolar disorder alters treatment prognosis. Psychiatr Q 2008;79(2):139-50.

[11] Braam AW, Copeland JR, Delespaul PA, Beekman AT, Como A, Dewey M, et al. Depression, subthreshold depression and comorbid anxiety symptoms in older Europeans: results from the EURODEP concerted action. J Affect Disord 2014; $155: 266-72$

[12] Saarni SI, Suvisaari J, Sintonen H, Pirkola S, Koskinen S, Aromaa A, et al. Impact of psychiatric disorders on health-related quality of life: general population survey. Br J Psychiatry 2007;190:326-32.

[13] Comer JS, Blanco C, Hasin DS, Liu S-M, Grant BF, Turner JB, et al. Health-related quality of life across the anxiety disorders. J Clin Psychiatry 2011;72(1):43-50.

[14] Karsten J, Penninx BW, Verboom CE, Nolen WA, Hartman CA. Course and risk factors of functional impairment in subthreshold depression and anxiety. Depress Anxiety 2013;30(4):386-94.

[15] Miloyan B, Byrne GJ, Pachana NA. Threshold and subthreshold generalized anxiety disorder in later life. Am J Geriatr Psychiatry 2015;23(6):633-41.

[16] Weiller E, Bisserbe JC, Maier W, Lecrubier Y. Prevalence and recognition of anxiety syndromes in five European primary care settings: a report from the WHO study on psychological problems in general health care. Br J Psychiatry Suppl 1998;34:18-23.

[17] Mantere O, Melartin TK, Suominen K, Rytsala HJ, Valtonen HM, Arvilommi P. et al. Differences in Axis I and II comorbidity between bipolar I and II disorders and major depressive disorder. J Clin Psychiatry 2006;67(4):584-93.

[18] Melartin TK, Rytsala HJ, Leskela US, Lestela-Mielonen PS, Sokero TP, Isometsa ET. Current comorbidity of psychiatric disorders among DSM-IV major depressive disorder patients in psychiatric care in the Vantaa Depression Study. J Clin Psychiatry 2002;63(2):126-34.
[19] Lysaker PH, Salyers MP. Anxiety symptoms in schizophrenia spectrum disorders: associations with social function, positive and negative symptoms, hope and trauma history. Acta Psychiatr Scand 2007;114(4):290-8.

[20] Krueger RF, Caspi A, Moffitt TE, Silva PA. The structure and stability of common mental disorders (DSM-III-R): a longitudinal-epidemiological study. J. Abnorm Psychol 1998;107(2):216-27.

[21] Krueger RF. The structure of common mental disorders. Arch Gen Psychiatry 1999;56(10):921-6.

[22] Melartin T, Mantere O, Ketokivi M, Isometsä E. A prospective latent analysis study of Axis I psychiatric co-morbidity of DSM-IV major depressive disorder. Psychol Med 2014;44(5):949-59.

[23] Eaton NR, Krueger RF, Markon KE, Keyes KM, Skodol AE, Wall M, et al. The structure and predictive validity of the internalizing disorders. J Abnorm Psychol 2013;122(1):86-92.

[24] Kessler RC, Ormel J, Petukhova M, McLaughlin KA, Green JG, Russo LJ, et al. Development of lifetime comorbidity in the WHO World Mental Health (WMH) Surveys. Arch Gen Psychiatry 2011;68(1):90-100.

[25] Kendler KS, Aggen SH, Knudsen GP, Røysamb E, Neale MC, Reichborn-Kjennerud $\mathrm{T}$. The structure of genetic and environmental risk factors for syndroma and subsyndromal common DSM-IV axis I and all axis II disorders. Am J Psychiatry 2011;168(1):29-39.

[26] Hettema JM. What is the genetic relationship between anxiety and depression? Am J Med Genet C 2008;148C(2):140-6.

[27] Mantere O, Soronen P, Uher R, Ketokivi M, Jylha P, Melartin T, et al. Neuroticism mediates the effect of P2RX7 on outcomes of mood disorders. Depress Anxiety 2012;29(9):816-23.

[28] Ormel J, Jeronimus BF, Kotov R, Riese H, Bos EH, Hankin B, et al. Neuroticism and common mental disorders: meaning and utility of a complex relationship. Clin Psychol Rev 2013;33(5):686-97.

[29] Griffith JW, Zinbarg RE, Craske MG, Mineka S, Rose RD, Waters AM, et al. Neuroticism as a common dimension in the internalizing disorders. Psychol Med 2010;40(7):1125-36.

[30] de Moor MH, van den Berg SM, Verweij KJ, Krueger RF, Luciano M, Arias Vasquez A, et al. Meta-analysis of genome-wide association studies for neuroticism, and the polygenic association with major depressive disorder. JAMA Psychiatry 2015;72(7):642-50.

[31] Hovens JG, Giltay EJ, Wiersma JE, Spinhoven P, Penninx BW, Zitman FG. Impact of childhood life events and trauma on the course of depressive and anxiety disorders. Acta Psychiatr Scand 2012;126(3):198-207.

[32] Richards JC, Richardson V, Pier C. The relative contributions of negative cognitions and self-efficacy to severity of panic attacks in panic disorder. Behav Change 2002;19(2):102-11.

[33] De Las Cuevas C, Penate W, Sanz EJ. The relationship of psychological reactance, health locus of control and sense of self-efficacy with adherence to treatment in psychiatric outpatients with depression. BMC Psychiatry 2014 $14: 324$

[34] Zanarini MC, Frankenburg FR, Dubo ED, Sickel AE, Trikha A, Levin A, et al. comorbidity of borderline personality disorder. Am J Psychiatry 1998;155(12): 1733-9.

[35] Marazziti D, Dell'osso B, Catena Dell'Osso M, Consoli G, Del Debbio A, Mungai F, et al. Romantic attachment in patients with mood and anxiety disorders. CNS Spectr 2007;12(10):751-6.

[36] Van Os J, Jones PB. Neuroticism as a risk factor for schizophrenia. Psychol Med 2001;31(6):1129-34

[37] Larsson S, Andreassen OA, Aas M, Røssberg JI, Mork E, Steen NE, et al. High prevalence of childhood trauma in patients with schizophrenia spectrum and affective disorder. Compr Psychiatry 2013;54(2):123-7.

[38] Kurtz MM, Olfson RH, Rose J. Self-efficacy and functional status in schizophrenia: relationship to insight, cognition and negative symptoms. Schizophr Res 2013;145(1-3):69-74.

[39] Bahorik AL, Eack SM. Examining the course and outcome of individuals diagnosed with schizophrenia and comorbid borderline personality disorder. Schizophr Res 2010;124(1-3):29-35.

[40] International classification of disease, 10th ed., Geneva: World Health Organization; 1992.

[41] Norman SB, Cissell SH, Means-Christensen AJ, Stein MB. Development and validation of an Overall Anxiety Severity and Impairment Scale (OASIS). Depress Anxiety 2006;23(4):245-9.

[42] Campbell-Sills L, Norman SB, Craske MG, Sullivan G, Lang AJ, Chavira DA, et al Validation of a brief measure of anxiety-related severity and impairment: the Overall Anxiety Severity and Impairment Scale (OASIS). J Affect Disord 2009:112(1-3):92-101.

[43] Beck AT, Ward CH, Mendelson M, Mock J, Erbaugh J. An inventory for measuring depression. Arch Gen Psychiatry 1961;4:561-71.

[44] Konstabel K, Lönnqvist J-E, Walkowitz G, Konstabel K, Verkasalo M, et al. The 'Short Five' (S5): measuring personality traits using comprehensive single items. Eur J Pers 2012;26(1):13-29.

[45] Fraley RC, Waller NG, Brennan KA. An item response theory analysis of selfreport measures of adult attachment. J Pers Soc Psychol 2000;78:350-65.

[46] Schwarzer R, Jerusalem M. Generalized Self-Efficacy scale. In: Weinman J, Wright S, Johnston M, editors. Measures in health psychology: A user's portfolio. Causal and control beliefs. UK: Windsor; 1995. p. 35-7.

[47] Zanarini MC, Vujanovic AA, Parachini EA, Boulanger JL, Frankenburg FR, Hennen J. A screening measure for BPD: the McLean Screening Instrument for Borderline Personality Disorder (MSI-BPD). J Pers Disord 2003;17(6): 568-73. 
[48] Patterson P, Skeate A, Schultze-Lutter F, Graf von Reventlow H, Wieneke A, Ruhrmann S, et al. The Trauma and Distress Scale. Birmingham, UK:University of Birmingham; 2002.

[49] Luutonen S, Tikka M, Karlsson H, Salokangas RK. Childhood trauma and distress experiences associate with psychotic symptoms in patients attending primary and psychiatric outpatient care. Results of the RADEP study. Eur Psychiatry 2013;28(3):154-60.

[50] IBM SPSS Statistics for Windows, Version 22.0. Released 2013. Armonk, NY: IBM Corp; 2013.

[51] Norman SB, Campbell-Sills L, Hitchcock CA, Sullivan S, Rochlin A, Wilkins KC et al. Psychometrics of a brief measure of anxiety to detect severity and impairment: The overall anxiety severity and impairment scale (OASIS). J Psychiatr Res 2011;45(2):262-8.

[52] Mantere O, Suominen K, Leppämäki S, Valtonen H, Arvilommi P, Isometsä E. The clinical characteristics of DSM-IV bipolar I and II disorders: baseline findings from the Jorvi Bipolar Study (JoBS). Bipolar Disord 2004;6(5):395-405.

[53] Mantere O, Isometsä E, Ketokivi M, Kiviruusu O, Suominen K, Valtonen HM, et al. A prospective latent analyses study of psychiatric comorbidity of DSM-IV bipolar I and II disorders. Bipolar Disord 2010;12(3):271-84.

[54] Reddy LF, Green MF, Rizzo S, Sugar CA, Blanchard JJ, Gur RE, et al. Behavioral approach and avoidance in schizophrenia: an evaluation of motivational profiles. Schizophr Res 2014;159(1):164-70.

[55] Konstantakopoulos G, Ploumpidis D, Oulis P, Patrikelis P, Soumani A, Papadimitriou GN, et al. Apathy, cognitive deficits and functional impairment in schizophrenia. Schizophr Res 2011;133(1-3):193-8.
[56] Hansen CF, Torgalsboen AK, Rossberg JI, Romm KL, Andreassen OA, Bell MD, et al. Object relations, reality testing, and social withdrawal in schizophrenia and bipolar disorder. J Nerv Ment Dis 2013;201(3):222-5.

[57] Foussias G, Agid O, Fervaha G, Remington G. Negative symptoms of schizophrenia: clinical features, relevance to real world functioning and specificity versus other CNS disorders. Eur Neuropsychopharmacol 2014;24(5): 693-709.

[58] Weber K, Rockstroh B, Borgelt J, Awiszus B, Popov T, Hoffmann K, et al. Stress load during childhood affects psychopathology in psychiatric patients. BMC Psychiatry 2008;8:63.

[59] McFarlane A, Clark CR, Bryant RA, Williams LM, Niaura R, Paul RH, et al. The impact of early life stress on psychophysiological, personality and behavioral measures in 740 non-clinical subjects. J Integr Neurosci 2005;4(1): 27-40.

[60] Roy A. Childhood trauma and neuroticism as an adult: possible implication for the development of the common psychiatric disorders and suicidal behavior. Psychol Med 2002;32(8):1471-4.

[61] Grant BF, Chou SP, Goldstein RB, Huang B, Stinson FS, Saha TD, et al. Prevalence, correlates, disability, and comorbidity of DSM-IV borderline personality disorder: results from the Wave 2 National Epidemiologic Survey on Alcohol and Related Conditions. J Clin Psychiatry 2008;69(4):533-45.

[62] Gallagher MW, Payne LA, White KS, Shear KM, Woods SW, Gorman JM, et al. Mechanisms of change in cognitive behavioral therapy for panic disorder: the unique effects of self-efficacy and anxiety sensitivity. Behav Res Ther 2013; 51(11):767-77. 